requiring for thelr due execulion scientific and refined processes and the superintendence of scientific men of high qualifications, are yet, properly speaking, rather applications of scientific views and acquired skill to particular objects of national importance, than undertakings of research having in view as their primary object the advancement of science itself. It is true, that as practice makes perfect, science does gain by such applications, and that by going somewhat out of the way in their execution, and seizing opportunities, most valuable theoretical results and data are occasionally elicited at an additional cost incomparably less than would be incurred by instituting operations for the purpose $a b$ initio. But when I consider the pregnant nature of scientific truth, and how upon occasion of every well-grounded accession to, or extension of, theoretical knowledge, a new practice has arisen founded thereon, and old methods have been abandoned as inefficient and unecononical in comparison, I should feel prepared to advocate or defend a very large and liberal devotion indeed of the public means to setting on foot undertakings, and maintaining establishments, in which the investigation of physical laws and data should be the avowed and primary object, and practical application the secondary, incidental, and collateral one.

"This, however, has hitherto been the fortunate lot of Astronomy only. And the result has been, not only the establishment of a complete theory-not only the perfection of nautical tables and observation-but an universal impulse given to every other branch of exact inquiry-a higher standard erected everywhere, a precision in every determination rendered practicable, which would have never before been dreamed of as attainable without the requirements of Astronomy. Is it hoping too much that the day may not be far distant when Physical Science in all its exacter branches shall participate in these advantages, and when the establishment of 'Physical Observatories' in our own and distant Jands shall give that impulse to many other sciences (as for example Magnetism, Meteorology, \&cc.) of which they stand so much in need ?" ....

"J. F. W. H."

\section{Trade Winds}

Maury, in his "Physical Geography of the Sea," maintains that the surface trade wind of the northern hemisphere becomes the uprer counter current of the south, and vice versit. That the trade winds, in fact, cross each other so-

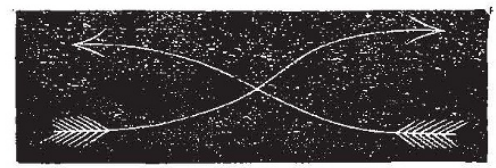

FrG. I.

instead of meeting and turning lack over themselves so-

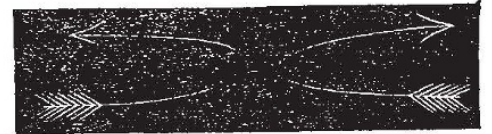

Fig. 2.

Subsequent writers on "physical geography have repeated this statement without apparently reflecting on its extreme improbability.

Maury's arguments for this strange theory are partly connected with the hygrometric state of certain of these currents, partiy with terrestrial magnetism, and partly with the nature of the airdust. It would take up too much of your space to discuss these points fully. The arguments founded on terrestrial magnetism are, however, purely hypothetical and very tanciful. Those on the hygrometric state of the currents are not very convincing. It is, however, to the latter of Maury's arguments I wish to draw your readers' attention. Maury seems to believe in this almost incredible direction of the air currents because Ehrenberg identified certain South American infusorial forms in the red dust which often falls at sea near the West Coast of Africa and in South Europe. Did Ehrenberg simply identify certain South American forms in the dust, or did he identify the dust as South American on account of the presence of these forms? If the former, the argument goes for little; South American forms may be found in Africa also. If the latter, then a new difficulty arises. Every microscopist knows the curious diversity of infusorial forms in all climates at all similar. It would be the height of presumption even to question the conclusions of Ehrenberg in microscopy; and yet to be able to identify infusorial forms in such a way as to say that dust containing them comes from such and such locality is certainly very wonderful.

Maury, from some of his"remarks, does "not seem to be fully alive to the utter inconsistency of his theory with what we know of the laws of fluid motion. That two broad flat rapid currents should encounter or flow into the same rising current and then cross through each other in alternate strips, or curdles, as Maury calls them, is scarcely within the bounds of physical possibility. On the other hand, Maury's opinions are certainly entitled to consideration, and this is one which he found with so much deliberation, and entertained so firmly, that I should gladly learn what competent physicists of the present day think of it.

Graeff Reinet College, Nov. 13

F. GUThrie

\section{The Arctic Expedition}

THE absence of sunlight during the Arctic winter is said to have an injurious effect on the health of both men and dogs; yet it does not appear that the best substitute for solar light has ever been employed for illuminating purposes during the dark season. It occurs to me that the occasional use of the electriclight would be likely to mitigate the evils due to the absence of solar radiation, and the constant use of oil lamps. If Gramme's electro-magnetic apparatus could be conveniently used on board ship, it would appear to offer the additional advantage of giving employment to the men at a time when it is difficult to find occupation for them.

Dublin, Feb. 23

R. J. Moss

\section{Herapath's Balance}

CAN any of your readers inform me whether Herapath completed his balance, in which he suspended the beam from a magnet; also whether the idea was taken up by balance makers? He gives an account of this form of balance in a paper dated I82 $\mathrm{T}$. E. W. P.

\section{OUR ASTRONOMICAL COLUMN}

THE BinaRy StaR $\mu^{2}$ Bootis.--Dr. W. Doberck, of Col. Cooper's Observatory, Markree Castle, Sligo, has communicated to the Royal Irish Academy, and also published in Ast. Nach. No. 2026, an orbit of this binary founded upon a very complete discussion of the measures from 1782 when the duplicity was detected by Sir W. Herschel, to 1873 . The resulting period of revolution is 290 years, and the true peri-astron passage is found to have occurred about 1863.5 . Dr. Doberck does not append an ephemeris of angles and distances according to his orbit, but we supply them for the next eighteen months for comparison with any measures that may be made in the interval :-

$$
\begin{array}{rcccc}
1875.25 & \text { Angle } & 144^{\circ} .79 & \text { Distance } & 0^{\prime \prime} \cdot 632 \\
75.75 & " & 142.83 & & 0.634 \\
76.25 & " & 140.89 & & 0.637 \\
76.75 & " & 138.96 & \# & 0.640
\end{array}
$$

FALB'S NEW VARIABLE IN ORION.-The star to which reference was made in NATURE last week, appears to be the preceding component of the double star $\Sigma 747$, or that which was the smaller star during Struve's measures 1825-36. Herr Falb has given some particulars relating. to this object in No. 2,026 of the Astronomische Nachrichten, but we suspect he has inadvertently reversed the order in which the magnitudes of the Dorpat Catalogue should be assigned. Struve's mean is

$$
1833^{\circ} 59 \text { Angle } 223^{\circ} .06 \text { Distance } 35^{\prime \prime} \cdot 85
$$


whence the smaller star was in the south-preceding quadrant. In addition to the authorities for magnitude quoted by Herr Falb, it may be mentioned that both components are found in the last Greenwich Catalogue (1864); the preceding star is there called $8 \mathrm{mag}$, and the following one 7. If we transform the differences of R.A. and N.P.D. in this catalogue into angle and distance, there results for about

I866.95 Angle $224^{\circ} \cdot 5$ Distance $36^{\prime \prime} \cdot 4$

agreeing as closely with Struve's measures as could be expected. The principal or following component of $\Sigma 747$ is Bradley 8or, and its position for the beginning of the present year is in R.A. $5 \mathrm{~h}, 28 \mathrm{~m} .54 \mathrm{~s}^{\circ} 4$, and N.P.L. $96^{\circ} 5^{\prime} 39^{\prime \prime}$; it is $8^{\prime}$ distant from $\iota$ Orionis, on an angle of $225^{\circ}$.

THE VARIABLE STAR R HYDRE,-Observations of this star in southern latitudes are much needed for affording a better insight into the law of variation than we yet possess. That the period has greatly diminished since the time of Maraldi is beyond doubt ; Schönfeld makes it about 500 days for the year 1708,487 days for 1785 , and 437 days for 1870 . It was pointed out by Argelander that good comparison stars are too low for favourable observation in central European latitudes. According to the formula involving $\mathrm{E}^{2}$ and $\mathrm{E}^{3}$, given in Schönfeld's last catalogue, a maximum would occur on the $25^{\text {th }}$ of February, and the following one falls 1876 , May so. The minimum, which by Schmidt's observations occurs 200 days before the maximum, will not be observable in the present year. At greatest brightness the star is found to vary from $4 \%$ to 5.5 . Its position for $\mathrm{J} 875$ is in R.A. I3h. $22 \mathrm{~m} .53 \mathrm{~s}$., and N.P.D. $112^{\circ} 38^{\prime} \circ$.

WINNECRE'S COMET.-This body is now beyond reach, and it is probable that the observations which have been secured will be few in number. It is nevertheless evident that the elements are very well determined, a very small acceleration which is also indicated in previous revolutions being sufficient to produce an exact agreement between Prof. Oppolzer's calculations and the result of the first Marseilles observation. Reference was lately made to the Vienna astronomer's suspicion of identity of this comet with one of the imperfectly observed comets of 1808 - that which was discovered by Pons on Feb. 6th and seen again on the 9 th. On examining the matter more closely there appears to be strong reasons to doubt this inference, upon which we may enter in a future notice.

ThE ZODTACAL LIGLT.- Another conspicuous exhibition of this phenomenon was observable in the neighbourhood of London on the evening of February 25. The sky was very vaporous, and the smaller stars usually visible without a telescope were not discerned, but soon after 8 P.M. the light was quite a marked object in the heavens: it did not present the lemon tinge which is commonly the case when the sky is clear, but rather resembled the light of the Milky Way, except that it was of much greater intensity. It could not be traced that evening beyond the constellation Musca.

New Minor Planet.-Le Verrier's Bulletin of Feb. 27 announces the discovery of a new member of the minor planet group by Herr Palisa at the Observatory of Pola on the $23 \mathrm{rd}$. Its position at $8 \mathrm{~h} .42 \mathrm{~m}$. local time was in R.A. 9h. $57 \mathrm{~m}$. 56s., N.P.D. $76^{\circ} 14^{\prime}$. The planet is of the twelfth magnitude.

\section{SCIENCE AT THE NEW PARIS OPERA}

THE New Paris Opera has excited a great deal of attention among all classes, both on the Continent and in England. Every effort has been made to make the building perfect in all respects, and to carry out its construction in harmony with the latest scientific princi- ples. Some recent numbers of $\mathrm{La}$ Nature contain a series of articles by $M$. G. Tissandier on the new building, to show in what manner the principles of science have been roade to conduce to the welfare and comfort of art. A few of the points in these articles we shall bring before our readers, as also some of the illustrations, which have been obligingly lent us by the proprietors of our sister journal. M. Tissandier deals first with the subject of Warming and Ventilation.

It is not astonishing that the ventilation of theatres has been effected in a very incomplete fashion, when we consider the difficulties which stand in the way of a complete solution. "A theatre is composed not of a single compartment, like every other place of assembly, but of three vast contiguous compartments : the hall (or auditorium), the corridors, and the stage, all which, at certain times are separated, at others connected by vast openings. To this first difficulty must be added the action of the lustre, which causes a strong current of sonorous waves towards the ceiling, greatly to the detriment of the acoustics and to the equality of temperature in the various parts of the auditorium. The position of the spectatcrs in tiers rising one above the other along the walls, and not horizontally, adds a new obstacle to the efficacious renewal of the air. Moreover, the conditions of the problem are constantly changing. Thus, before the entrance of the public the heating may have taken place downwards and by the ordinary means; but, once the public have been admitted and the curtain raised, a considerable mass of air, that of the stage, is put into communication with the body of the theatre. Between the acts this communication ceases; but, on the other hand, there are from $I, 000$ to $I, 500$ persons, just so many living stoves, and some hundreds of gas-jets, which heat and gradually vitiate the atmosphere. Hence a change must be introduced in the ventilation; still another change when the curtain is raised; and all this to be modified according to the season." *

At the commencement of the present century the Marquis de Chavannes devised a system, which was tried at Covent Garden Theatre, and which contained the principle of all the methods since invented.

The heating of the stage was effected by steam cylinders, shown at $M$, in Fig. $x$. Ventilation took place at $\mathrm{N}$ above. The auditorium was heated by the large stove $B$, which by cylindrical pipes sends warm air under the flooring of the boxes and into the staircases. At $R$ the vitiated air of the boxes met, drawn off by the openings A AA. The vitiated air of the body of the theatre drawn upwards by the lustre, reached $Q$, after having traversed the openings $\mathrm{P} P$.

In 1828 a commission, composed of Bérard, Cadet de Gassicourt, Marc, and d'Arcet, was entrusted in France with an investigation into the principles of the ventilation of theatres. Fig. 2 represents the arrangement devised by d'Arcet, who took advantage of the lustre to convey outside the air vitiated by the combustion and by the breath of the audience. The warm air is introduced into the corridors by the openings $\mathrm{C} \mathrm{C} \mathrm{C}$; it enters the auditorium by passing under the flooring of the boxes, in the direction of the arrows. The exit of the air takes place at $U$; it may be regulated above the lustre by means of the movable traps at $T$. It is also accomplished at $V$, by passages which are united in the central chimney.

These systems had serious drawbacks. An attempt at improvement was made in $186 \mathrm{I}$, during the construction of the new theatres in the Place du Chatelet. For the purpose of investigating the question a commission was nominated, presided over by M. Dumas, Perpetual Secretary of the Academy of Sciences, and having for reporter General Morin, Director of the Conservatoire des Arts et Métiers. After many experiments and many contra-

* "Traité pratique du chauffage et de la ventilation," by V. Ch. Joly. 